\title{
EPIDEMIOLOGY OF CLEFT LIP AND PALATE AND RARE FACIAL CLEFTS IN UPPER ASSAM: A HOSPITAL BASED STUDY
}

\author{
Utpal Kumar Bordoloi ${ }^{1}$, Rubi Saikia ${ }^{2}$
}

${ }^{1}$ Associate Professor, Department of Plastic Surgery, Assam Medical College, Dibrugarh, Assam, India. ${ }^{2}$ Associate Professor, Department of Anatomy, Jorhat Medical College, Jorhat, Assam, India.

\begin{abstract}
Cleft Lip and Palate and Rare Facial clefts occur in varying degree of severity and variety of patterns. It's a nightmare which every parent wants to avoid. Facial clefts occur when the structures contributing to the formation of face namely-the frontonasal prominence, the maxillary prominence, the medial nasal prominence, the lateral nasal prominence, and the mandibular prominences fail to fuse with one another. These defects result in abnormal facial appearance, difficulties in feeding, defective dentition, defective speech, repeated ear and respiratory tract infections, and social stigma. In this study, an attempt has been made to know the prevalence rate of Cleft Lip and Palate and Rare Facial clefts as well as its sexual dimorphism in upper (eastern) Assam. The study was carried out from January 2008 to June 2014 among the 781 cases of facial clefts who attended the Smile Train Centre in Srishti Hospitals, Dibrugarh, Upper Assam, India. It was found that isolated cleft lip (41.22\%) occurred more commonly than isolated cleft palate (17.41\%). Cleft lip was more common in males (63.97\%) than in females (36.02\%). 312 (39.94\%) of the cases presented with both cleft lip and palate and among these 188 (60.25\%) were females and 124 (39.74\%) were males. Isolated cleft palate was found to be more common in females (68.38\%) than in males (31.61\%). All these cases underwent reconstructive surgery and left the hospital smiling with a sociably presentable face.
\end{abstract}

\section{KEYWORDS}

Facial Clefts, Frontonasal, Maxillary, Mandibular, Lateral Nasal, Medial Nasal, Tessier Cleft.

HOW TO CITE THIS ARTICLE: Bordoloi UK, Saikia R. Epidemiology of cleft lip and palate and rare facial clefts in upper assam: a hospital based study. J. Evolution Med. Dent. Sci. 2016;5(66):4735-4739, DOI: 10.14260/jemds/2016/1079

\section{INTRODUCTION}

The face in a human embryo is formed by fusion of some facial processes that appear in the $4^{\text {th }}$ week of development. The epithelial union of the processes are reinforced by mesodermal migration from the neural tube region, which prevent disruption of epithelial union. The frontonasal prominence forms the forehead, bridge of the nose, medial, and lateral nasal prominences. The maxillary prominence forms the cheeks and lateral portion of upper lip. The medial nasal prominence forms the philtrum of upper lip, crest, and tip of nose while the lateral nasal prominence forms the ala of nose. The mandibular prominence forms the entire lower lip and jaw. Different types of cleft lip result if the medial nasal prominence fail to fuse with the maxillary prominences. Bilateral cleft lip occurs due to failure of both maxillary processes to fuse with the medial nasal prominence, which then appears as a separate flap. Failure of whole maxillary prominence to fuse with the lateral margin of the lateral nasal prominence results in an oblique facial cleft. Cleft palate results due to failure of fusion of the palatine shelves with each other or with the anterior triangular primary palate. However, all rare facial clefts cannot be explained by failure of fusion of facial processes. Cleft lip and cleft palate are one of the most common congenital deformities. The incidence of cleft lip is approximately $1 / 1000$ births and it occurs more frequently in males $(80 \%)$ than in females. The incidence of cleft palate is

Financial or Other, Competing Interest: None.

Submission 11-07-2016, Peer Review 04-08-2016,

Acceptance 10-08-2016, Published 18-08-2016.

Corresponding Author:

Dr. Utpal Kumar Bordoloi,

Associate Professor,

Department of Plastic Surgery,

Assam Medical College,

Dibrugarh-786002, Assam, India.

E-mail: utpalbordoloi50@gmail.com

DOI: $10.14260 /$ jemds/2016/1079 approximately $1 / 2500$ births and occurs more often in females $(67 \%)$ than in males.(1,2) To have a child with grossly deformed face is certainly a horrifying experience for the entire family. For all such children, the problem goes beyond the obvious disfigurement of the face to repeated infections, social stigma, problems with speech, hearing, and teeth formation.(3) These children are often teased by their friends and they lose self-confidence. They suffer with emotional "burn out" in adolescence.(4) Children with clefts often suffer from anaemia and malnutrition mainly due to poverty and illiteracy on the part of the parents. In addition, due to lack of awareness, many patients of cleft remain untreated or mistreated by quacks.(5) All children born with a cleft lip or palate need a thorough paediatric assessment to exclude other congenital abnormalities. Genetic counseling must be sought if a syndrome is suspected. Keeping in mind that no studies regarding the incidence of cleft lip and palate are published from this part of Assam, India. This study was undertaken to form a clinical picture of the patients specific to this region for the benefit of public and the treating doctors.

\section{MATERIALS AND METHODS:}

This study was carried out among the 781 cases of facial clefts who attended the Smile Train Centre at Srishti Hospitals, Dibrugarh, Assam, India, from January 2008 to June 2014. All the cases were evaluated on the basis of sex, religion, race, type of cleft, severity of the cleft, family history of facial clefts, birth order, consanguinity, maternal age, associated disease, radiation exposure, and drug history during $1^{\text {st }}$ trimester of pregnancy. Also, the socioeconomic status, parent's literacy, source of information for treatment, and parent's satisfaction after treatment was noted down. The aim and objective of this study was

1. To study the prevalence of isolated cleft lip.

2. To study the prevalence of isolated cleft palate.

3. To study the prevalence of cleft lip with cleft palate. 
4. To study the prevalence of rare facial clefts.

5. To study the result of surgical correction.

\section{RESULT AND OBSERVATIONS}

The data collected were tabulated and analysed as follows

\begin{tabular}{|c|c|c|c|c|c|}
\hline \multicolumn{2}{|c|}{ Male } & \multicolumn{2}{|r|}{ Female } & \multicolumn{2}{|c|}{ Total } \\
\hline $438(56$. & $8 \%)$ & & $343(43.91 \%)$ & & 81 \\
\hline \multicolumn{6}{|c|}{ Table 1: Showing Sex Distribution of the Cases } \\
\hline $\begin{array}{l}\text { Isolated } \\
\text { Cleft Lip }\end{array}$ & \multicolumn{2}{|c|}{$\begin{array}{l}\text { Isolated } \\
\text { Cleft } \\
\text { Palate }\end{array}$} & $\begin{array}{c}\text { Cleft Lip } \\
\text { with left } \\
\text { Palate }\end{array}$ & $\begin{array}{l}\text { Rare } \\
\text { Facial } \\
\text { Clefts }\end{array}$ & Total \\
\hline $\begin{array}{c}322 \\
(41.22 \%)\end{array}$ & \multicolumn{2}{|c|}{$\begin{array}{c}136 \\
(17.41 \%)\end{array}$} & $\begin{array}{c}312 \\
(39.94 \%)\end{array}$ & $\begin{array}{c}11 \\
(1.40 \%)\end{array}$ & 781 \\
\hline \multicolumn{6}{|c|}{ Table 2: Showing Types of Facial Clefts } \\
\hline
\end{tabular}
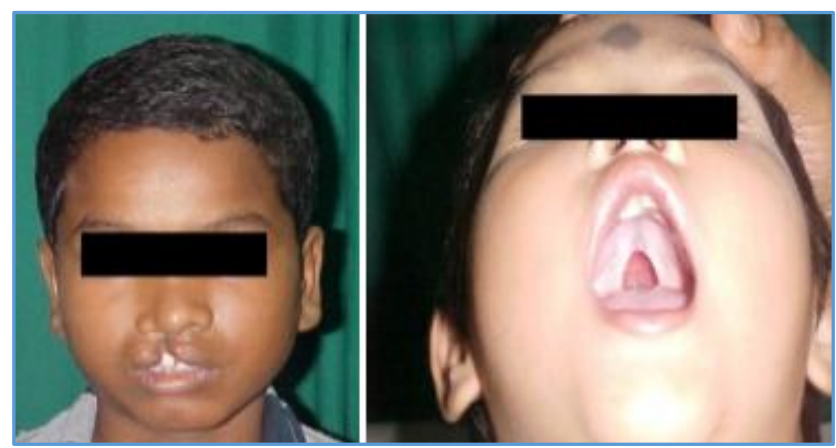

Fig.1: Isolated Right-Sided Incomplete Cleft Lip Fig.2: Isolated Cleft Palate, Incomplete

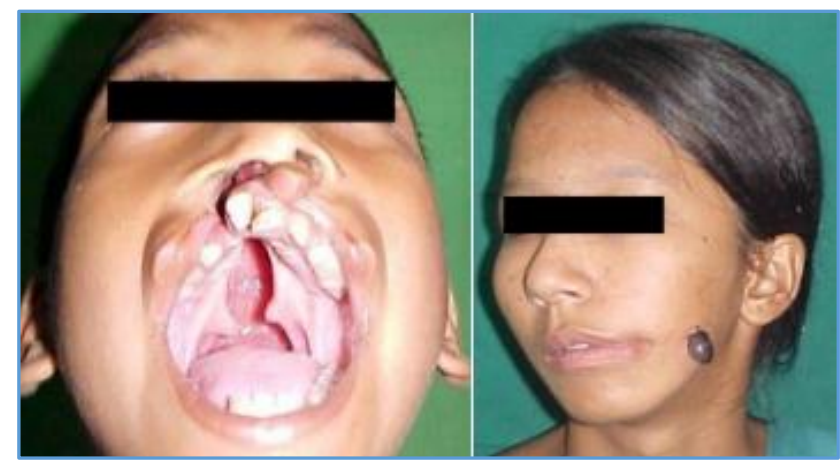

Fig.3: Right-Sided Complete Cleft Lip and Palate Fig 4: A Rare Facial Cleft, Tessier's Cleft 6

\begin{tabular}{|c|c|c|}
\hline Unilateral & Bilateral & Total \\
\hline $293(90.99 \%)$ & $29(9 \%)$ & 322 \\
\hline Table 3: Showing Side Distribution of Cleft Lip (CL) \\
\hline
\end{tabular}

\begin{tabular}{|c|c|c|}
\hline Right Sided & Left Sided & Total \\
\hline $115(39.24 \%)$ & $178(60.75 \%)$ & 293 \\
\hline \multicolumn{2}{|r|}{ Table 4: Showing Side Distribution of } \\
Unilateral Cleft Lip \\
\hline
\end{tabular}

\begin{tabular}{|c|c|c|c|c|}
\hline \multicolumn{2}{|c|}{ Right side } & \multicolumn{2}{c|}{ Left side } & Total \\
\hline Complete & Incomplete & Complete & Incomplete & \\
\hline 37 & 78 & 65 & 113 & 293 \\
\hline \multicolumn{2}{|c|}{ Table 5: Showing Completeness of Unilateral Cleft Lip } \\
\hline
\end{tabular}

\begin{tabular}{|c|c|c|}
\hline Sex & No. of Cases & Total \\
\hline Male & $206(63.97 \%)$ & \multirow{2}{*}{322} \\
\hline Female & $116(36.02 \%)$ & \\
\hline \multicolumn{2}{|c|}{ Table 6: Showing Sex Distribution of Cleft Lip } \\
\hline
\end{tabular}

\begin{tabular}{|c|c|c|}
\hline Sex & No. of Cases & Total \\
\hline Male & $124(39.74 \%)$ & \multirow{2}{*}{312} \\
\hline Female & $188(60.25 \%)$ & \\
\cline { 1 - 1 } Table 7: Showing Sex Distribution of \\
Cleft Lip with Cleft Palate \\
\hline
\end{tabular}

\begin{tabular}{|c|c|c|c|c|}
\hline \multicolumn{2}{|c|}{ Unilateral } & \multicolumn{2}{c|}{ Bilateral } & Total \\
\hline Complete & Incomplete & Complete & Incomplete & \multirow{2}{*}{616} \\
\hline 355 & 232 & 11 & 18 & \\
\hline \multicolumn{2}{|c|}{ Table 8: Showing Type of Cleft Lip with Cleft Palate } \\
\hline
\end{tabular}

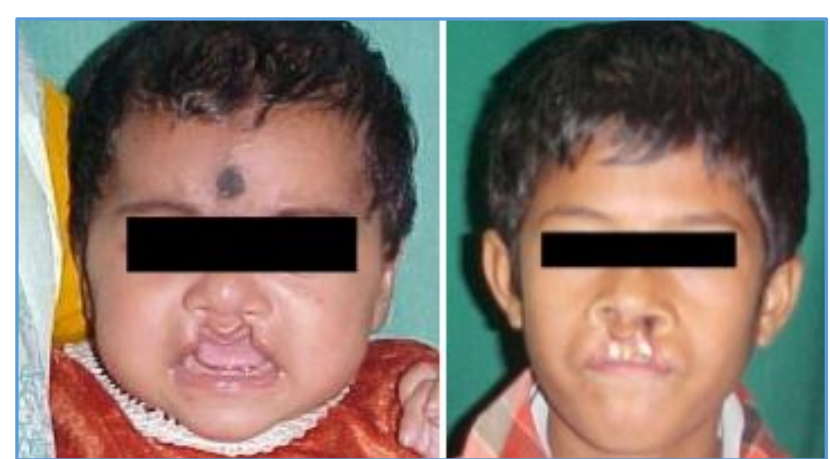

Fig.5: Bilateral Incomplete Cleft Lip Fig.6: Bilateral Complete Cleft Lip

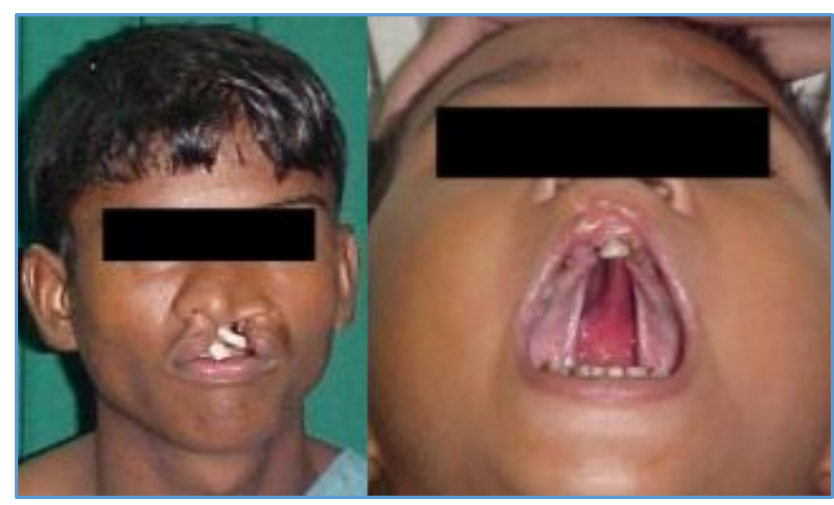

Fig. 7: Left-Sided Complete Cleft Lip Fig.8: Complete Cleft Palate

\begin{tabular}{|c|c|c|}
\hline Sex & No. of Cases & Total \\
\hline Male & $43(31.61 \%)$ & \multirow{2}{*}{136} \\
\hline Female & $93(68.38 \%)$ & \\
\hline \multicolumn{2}{|c|}{ Table 9: Showing Sex Distribution of } \\
Isolated Cleft Palate \\
\hline
\end{tabular}

\begin{tabular}{|c|c|c|}
\hline Complete & Incomplete & Total \\
\hline 312 & 136 & 448 \\
\hline \multicolumn{2}{|c|}{ Table 10: Showing Type of Cleft Palate } \\
\hline
\end{tabular}

As for family history, none of the family reported that the parents had cleft lip and palate. The age of the cases ranged from 3 months to 25 years in our study. The maternal age ranged between $18-39$ years.

\begin{tabular}{|c|c|}
\hline Anaemia & 380 \\
\hline Delayed milestone & 40 \\
\hline Mental retardation & 2 \\
\hline Respiratory illness & 62 \\
\hline Ear infection & 10 \\
\hline Under weight for age & 152 \\
\hline $\begin{array}{c}\text { Associated congenital } \\
\text { anomaly }\end{array}$ & 1 \\
\hline \multicolumn{2}{|c|}{ Table 11: Showing Associated Illness } \\
\hline
\end{tabular}




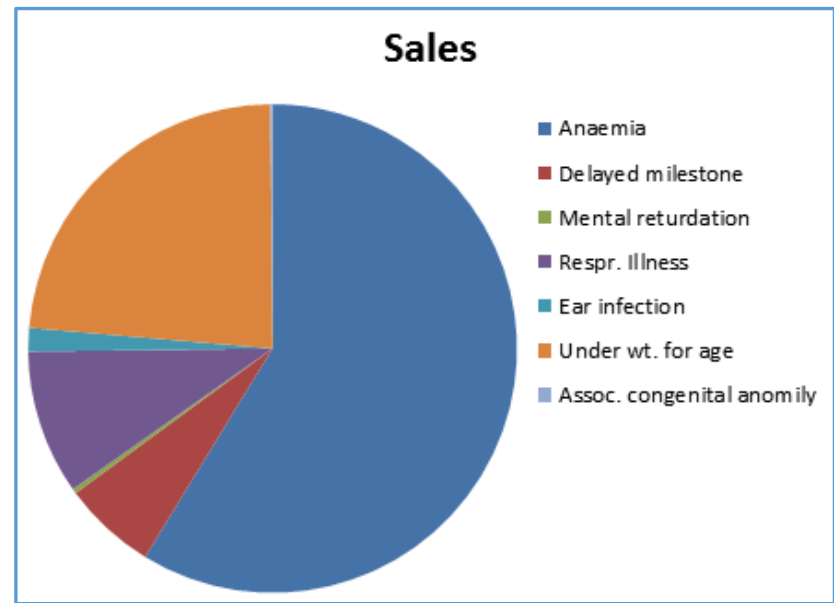

Graphical Representation of Associated Illness

More than half of the cases were suffering from anaemia.

\begin{tabular}{|c|c|c|}
\hline Hb. (gm\%) & $\begin{array}{c}\text { Number of } \\
\text { Cases }\end{array}$ & Percentage \\
\hline $7-8$ & 36 & $4.6 \%$ \\
\hline $8.1-9$ & 232 & $29.7 \%$ \\
\hline $9.1-10$ & 210 & $26.8 \%$ \\
\hline $10.1-11$ & 135 & $17.2 \%$ \\
\hline $11.1-12$ & 95 & $12.1 \%$ \\
\hline $12.1-13$ & 73 & $9.3 \%$ \\
\hline \multicolumn{2}{|c|}{ Table 12: Haemoglobin Level of the Patients } \\
\hline
\end{tabular}

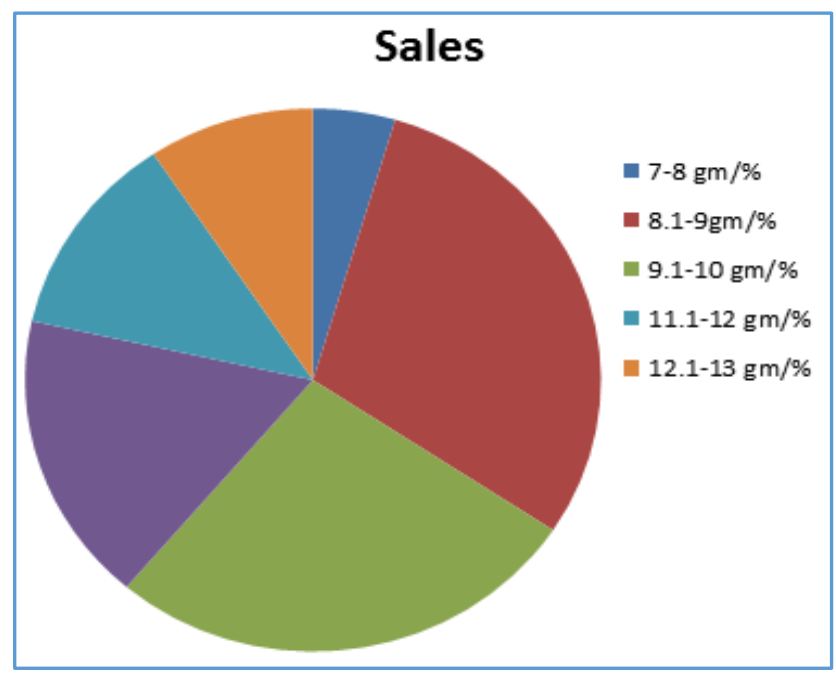

Graphical Representation of the Haemoglobin Level

It was found that majority of the cases were suffering from anaemia. Approximately, $21.4 \%$ of the cases had the haemoglobin level ranging between 11 to $13 \mathrm{gm} \%$.

\begin{tabular}{|c|c|c|}
\hline Type & $\begin{array}{c}\text { Number of } \\
\text { Cases }\end{array}$ & Total \\
\hline Tessier cleft 3, bilateral & 1 & \multirow{4}{*}{11} \\
\hline Tessier cleft 3 and 4 & 1 & \\
\hline Tessier cleft 4 & 1 & \\
\hline Tessier cleft 7 & 8 & \\
\hline
\end{tabular}

In the present study, we found that only 11 of the total 781 cases had rare facial clefts as mentioned in table 14.

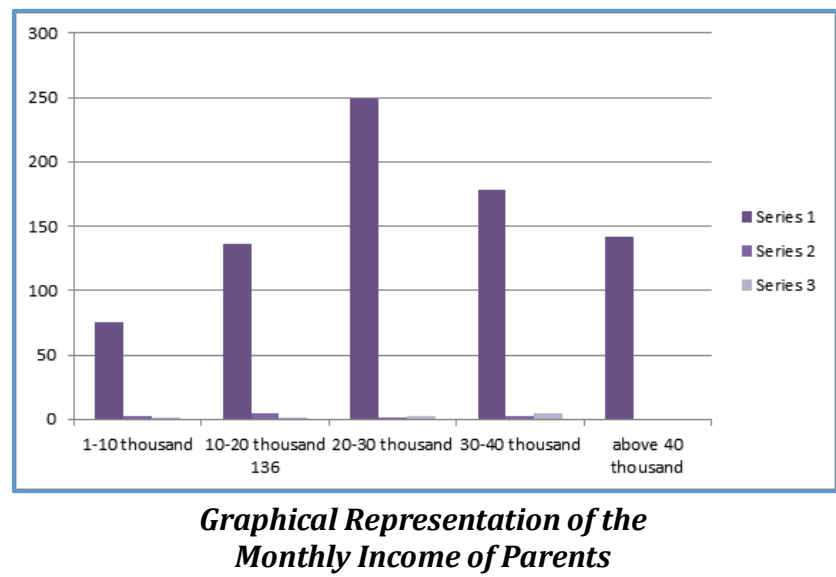

Thus, from the data summarised in the different tables, it is seen that majority of the cleft patients were males. Most of the families said that they came to know about the treatment facilities from friends and also from advertisements in radio and television. Since majority of them were of lower socioeconomic status, they were grateful that such free treatment was available at their doorstep. The study also shows that $0.64 \%$ of parents of children with facial clefts were absolutely illiterate, $37.77 \%$ of parents were undergraduates, and $61.58 \%$ of parents were graduates. As for maternal antenatal history, $43 \%$ of women never took iron and folic acid during pregnancy, $31 \%$ of women took the same, but irregularly and the rest $26 \%$ of women regularly supplemented their nutritional requirements as per advice of their doctors. The age of the mother ranged from 18 to 39 years in this study and 48 were consanguineous marriages.

\begin{tabular}{|c|c|c|}
\hline Race or Tribe & No. of Cases & Percentage \\
\hline $\begin{array}{l}\text { Tea garden } \\
\text { community }\end{array}$ & 167 & $21.28 \%$ \\
\hline $\begin{array}{c}\text { Assamese } \\
\text { (general) }\end{array}$ & 96 & $12.29 \%$ \\
\hline Ahom & 171 & $21.89 \%$ \\
\hline Mishing & 89 & $11.39 \%$ \\
\hline Kachari & 59 & $7.55 \%$ \\
\hline Bengali & 48 & $6.14 \%$ \\
\hline Bihari & 29 & $3.71 \%$ \\
\hline Nepali & 30 & $3.84 \%$ \\
\hline Arunachali & 47 & $6.01 \%$ \\
\hline Naga & 32 & $4.09 \%$ \\
\hline Mizo & 13 & $1.66 \%$ \\
\hline \multicolumn{3}{|c|}{$\begin{array}{c}\text { Table 14: Showing Ethnic Distribution of Cleft Lip and } \\
\text { Palate in Upper Assam }\end{array}$} \\
\hline
\end{tabular}

As can be seen, facial clefts are more common among the Ahom community $(21.89 \%)$ and the Tea garden community (21.28\%) of Assam as compared to others.

\begin{tabular}{|c|c|}
\hline Type of Operation & No. of Cases \\
\hline Rotation and Advancement & 232 \\
\hline Triangular variant & 355 \\
\hline Straight line repair & 29 \\
\hline Fisher repair & - \\
\hline $\begin{array}{c}\text { Rose Thompson (Oxford } \\
\text { modification) repair }\end{array}$ & - \\
\hline Table 15: Type of Surgery Done in Cases with Cleft Lip \\
\hline
\end{tabular}




\begin{tabular}{|c|c|}
\hline Type of Operation & No. of Cases \\
\hline Rose Thompson (Veau III) & 11 \\
\hline Straight line repair & 5 \\
\hline Forked flap & 2 \\
\hline Two stage repair & 11 \\
\hline \multicolumn{2}{|c|}{$\begin{array}{c}\text { Table 16: Type of Surgery Done in Cases of Bilateral } \\
\text { Cleft Lip }\end{array}$} \\
\hline
\end{tabular}

\begin{tabular}{|c|c|}
\hline Type of Operation & No. of Cases \\
\hline Veau-Kilner-Wardill & 34 \\
\hline Furlow's procedure & 12 \\
\hline Delaire two-stage repair & 36 \\
\hline Langenbeck procedure & 120 \\
\hline Push back procedure & 246 \\
\hline Table 17: Type of Surgery Done in Cases of Cleft Palate \\
\hline
\end{tabular}

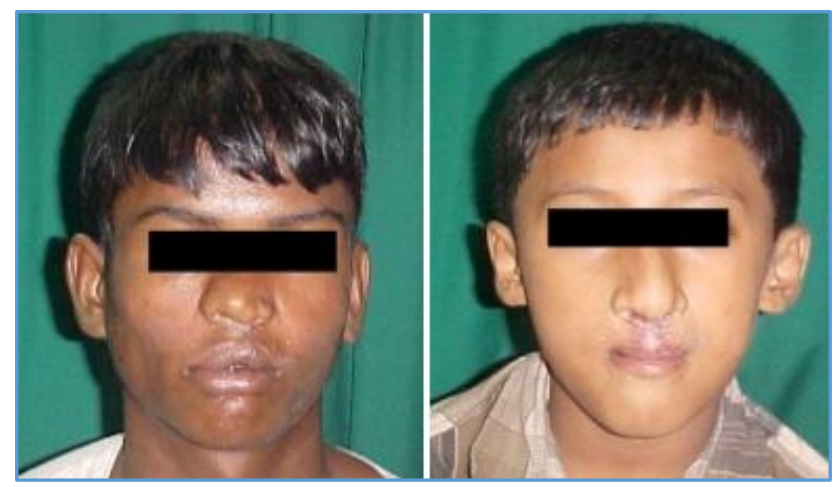

Fig. 9: Postoperative Case of Cleft lip Fig.10: Postoperative Case of Bilateral Cleft Lip

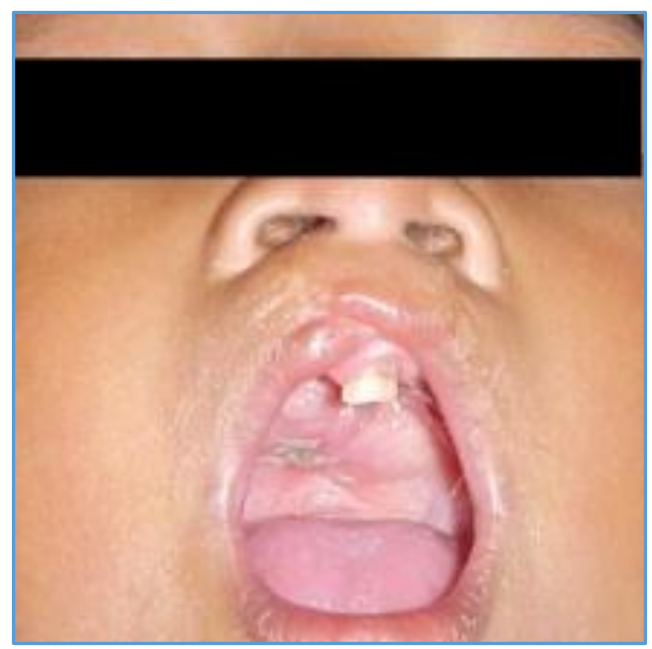

Fig.11: Postoperative Case of Cleft Palate

\begin{tabular}{|c|c|}
\hline Complications & No. of Cases \\
\hline Wound dehiscence & 6 \\
\hline Bleeding & 2 \\
\hline Scar hypertrophy & 32 \\
\hline Cupids bow defect & 8 \\
\hline Residual nasal deformity & 82 \\
\hline \multicolumn{2}{|c|}{ Table 18: Complications of Cleft Lip Surgery } \\
\hline
\end{tabular}

\begin{tabular}{|c|c|}
\hline Complications & No. of Cases \\
\hline Bleeding & 4 \\
\hline Dehiscence & 12 \\
\hline Fistula & 10 \\
\hline Table 19: Complications of Cleft Palate Surgery \\
\hline
\end{tabular}

Operations for wound dehiscence, fistula, and residual nasal deformity are not included in the present study.

\section{DISCUSSION}

Cleft lip and palate are a challenge to the surgeons. Due to illiteracy, facial clefts are still presumed to be a curse of God by various sections of the society mainly in remote areas. Review of studies shows that there is no particular trend for incidence of cleft lip and palate in different parts of the world. According to a WHO study on craniofacial anomalies carried out in 13 countries, the incidence varies from 0.22 to 1.67 per thousand live births.(6)

According to available literature, the incidence of cleft lip and palate exhibit ethnic variation. It is found to be highest in Asian or Native North American descents followed by the Caucasians. It is least among the Africans.(7) In the present study, we found it to be bore common in Ahom community and the Tea garden community of Assam.

Fogh Andersen(8) reported that siblings of patients with cleft lip and palate have an increased incidence of cleft lip and palate, but not isolated cleft palate; conversely, siblings of patients with cleft palate have an increased frequency of cleft palate, but not of cleft lip and palate. He also found that 30 $40 \%$ of 703 patients with cleft lip or cleft palate in Denmark had near relative with similar deformities. But in the present study, only $0.12 \%$ of 781 cases had near relative with similar deformity.

As for sex ratio, there is an excess of cleft lip and palate in males. Female excess has been reported in isolated cleft palate. $(8,9,10)$ The findings of our study is also similar. Cleft lip occurred more in males (63.97\%) than in females (36.02\%). Cleft palate occurred in a higher frequency in females $(68.38 \%)$ than in males $(31.61 \%)$.

As noted by Fogh-Andersen(8) and confirmed by many other studies, $(9,10,11,12,13)$ there is a left-sided preponderance of cleft lip. In this study, also cleft lip was more $(60.75 \%)$ on the left side and less (39.24\%) on the right side.

Patients of facial clefts are brought for surgery later than the ideal surgical time, which may be due to ignorance, poverty, or unawareness about the fact that such anomaly can be corrected by surgery. Without repair, these children would have suffered from social isolation, feeding problem, abnormal speech, repeated infections.(14) Many patients do not come to the hospital because they can't afford the treatment offered. May be, this is the reason why the maximum age was 25 years in our study.

As stated earlier, we also enquired about the type of marriage and found that consanguineous marriage is a common practice among the Muslim population of the state. $6.14 \%$ of parents confirmed it which could be a reason for having siblings with cleft lip and palate.(15)

To correct the facial clefts in our study, different standard operative procedures were followed.(16,17,18,19,20,21) Majority of the cleft palate cases (246) were corrected by pushback procedure followed by Langenbeck procedure (120 cases). Among the bilateral cleft lip cases, 11 each were corrected by Rose Thompson (Veau III) and two-stage repair procedures. All operations were successful except for a few minor complications in some, which were corrected subsequently.

\section{CONCLUSION}

Cleft lip and palate is no longer considered as stigma as these deformities can be corrected with various surgical procedures. 
Most of these operations take about 45 minutes to one and a half an hours' time. It was found that, cleft lip and palate is more common in males in the left side. However, isolated cleft palate is more common in females. Transverse facial cleft was the most common rare facial cleft in our study. Amongst the cases, anaemia is the most commonly associated condition followed by underweight for age and respiratory illness. Similarly, maternal malnutrition and anaemia was also commonly seen. There was no incidence of cleft lip and palate amongst the parents in our study. Most of the cases belonged to lower socioeconomic group. Assam is a multi-ethnic society and out of 781 cases we studied, highest number of cases were from Ahom community (171) followed by Tea-garden community (167). Various operative procedures were performed for cleft lip and cleft palate. All cases were done under general anaesthesia. Cleft lip and cleft palate operations were done in separate stages. Rotation and Advancement and Triangular flap procedures were most commonly done for cleft lip whereas Langenbeck and Pushback operations were the most commonly done operations for cleft palate. Rose Thompson (Veau III) and two staged repair procedures were most commonly done in bilateral cleft lip. In our study, commonly encountered complications for cleft lip included scar hypertrophy and residual nasal deformity and for cleft palate fistula.

\section{REFERENCES}

1. Sadler TW. Langman's medical embryology. $11^{\text {th }}$ edn Lippincott Williams and Wilkins 2011:280-7.

2. Hamilton WJ, Boyd JD, Mossman HW. Hamilton, Boyd and Mossman's human embryology: prenatal development of form and function. $4^{\text {th }}$ edn. London: The Macmillan Press Ltd 1978:293-302.

3. Dvivedi J, Dvivedi S. A clinical and demographic profile of cleft lip and palate in Sub-Himalayan India: a hospitalbased study. IJPS 2012;45(1):115-20.

4. Sridhar K. A community-based survey of visible congenital anomalies in rural Tamil Nadu. Indian Journal of Plastic Surg 2009;42(3):184-91.

5. Vasan N. Management of children with clefts of the lip or palate: an over view. NZ Dent J 1999;95(419):14-20.

6. Global strategies to reduce the healthcare burden of craniofacial anomalies. Report of WHO meetings on international collaborative research on craniofacial anomalies. Geneva, Switzerland, 2000.
7. Gorlin RJ, Cohen MM, Hennekem RC. Monographs on medical genetics syndromes of the head and neck. Minneapolis, USA: Oxford University Press 2001.

8. Fogh-Andersen P. Inheritance of harelip and cleft palate. Copenhagen: Arnold Busck 1942.

9. Fraser CR, Calnan JS. Cleft lip and palate: seasonal incidence, birth weight, birth rank, sex, site, associated malformations, and parental age. A statistical survey. Arch Dis Child 1961;36:420-3.

10. Blanco-Davita F. Incidence of cleft lip and palate in the North West of Mexico: a 10-year study. J Craniofacial Surg 2003;14(4):533-7.

11. Ingalls TH, Taube IE, Klingberg MA. Cleft lip and cleft palate: epidemiologic considerations. Plast Reconstr Surg 1964;34:1-10.

12. Fraser FC. The genetics of cleft lip and cleft palate. Am J Hum Genet 1970;22(3):336-52.

13. Wilson ME. A ten-year survey of cleft lip and cleft palate in South West region. Br J Plast Surg 1972;25(3):224-8.

14. Gupta K, Bansal P, Dev N, et al. Smile train project: a blessing for population of lower socioeconomic status. J Indian Medical Assoc 2010;108(11):723-5.

15. Reddy SG, Reddy RR, Bronkhorst EM, et al. Incidence of cleft lip and palate in the state of Andhra Pradesh, south India. Indian J of Plastic Surg 2010;43(2):184-9.

16. Brown JB, McDowell F. Small triangular flap operation for primary repair of single cleft lips. Plast Reconst Surg 1950;5(5):392-402.

17. Back C, Jesser J. Plastic surgery of face. Int J Orthod Oral Surg 1921;7:81.

18. Braurer RO, Cronin TD. Maxillary orthopaedics and anterior palate repair with bone grafting. Cleft Palate J 1964;16:31-42.

19. Cronin TD. Method of preventing raw area on nasal surface of soft palate in push back surgery. Plast Reconstr Surg 1957;20(6):474-84.

20. Devise D. The repair of the unilateral cleft lip. Br J Plast Reconstr Surg 1968;18:254.

21. Dorrence GM, Brensfield JW. The push back operation for repair of cleft palate. Plast Reconstr Surg 1946;1:145. 